\title{
Comunicação \\ Enraizamento de estacas caulinares e radiculares de Rubus fruticosus tratadas com AIB
}

\author{
Maraísa Hellen Tadeu ${ }^{1}$, Rafael Pio², Andrei Spaziani Tiberti ${ }^{1}$, Madeleine Alves de Figueiredo ${ }^{3}$, \\ Filipe Bittencourt Machado de Souza ${ }^{3}$
}

\section{RESUMO}

O objetivo deste trabalho foi avaliar o enraizamento de estacas caulinares e radiculares de Rubus fruticosus, tratadas com AIB. Estacas radiculares e caulinares dessa espécie foram coletadas em março, tendo posteriormente suas bases tratadas com diferentes concentrações de ácido indolbutírico (AIB, 1000, 2000, 3000 e $4000 \mathrm{mg} \mathrm{L}^{-1}$ ) por 10 segundos. O tratamento controle foi baseado somente no uso da água. As estacas caulinares foram enterradas a 2/3 de seu comprimento, em posição vertical, e as radiculares foram totalmente enterradas, na horizontal, utilizando-se a vermiculita ${ }^{\circledR}$ como substrato, em telado com sombreamento de 50\%. Após 60 dias, pôde-se concluir que as estacas caulinares apresentaram melhores resultados para formação das mudas, não se devendo tratá-las com AIB.

Palavras-chave: propagação assexuada, estaquia, ácido indolbutírico.

\section{ABSTRACT}

\section{Rooting of stems and root cuttings of Rubus fruticosus using IBA}

The objective of the present work was to evaluate the rizogenic potential for stems and root cuttings of Rubus fruticosus treated with indolbutyric acid. Roots and stems cuttings of this specie were collected in March, and had their basal portions treated with different concentrations of indolbutyric acid (IBA) (1000, 2000, 3000 and $\left.4000 \mathrm{mg} \mathrm{L}^{-1}\right)$ for 10 seconds. The control treatment used only water. The stem cuttings were planted with $2 / 3$ of their length in the vertical position and the root cuttings were totally covered in the horizontal position, using vermiculite as substrate, in screenhouse with $50 \%$ of shade. After 60 days, the stem cuttings presented better results for seedling formation, without IBA.

Key words: assexual propagation, cuttings, indolbutyric acid.

\footnotetext{
Recebido para publicação em 01/06/2012 e aprovado em 31/10/2012.

${ }^{1}$ Graduandos em Agronomia. Universidade Federal de Lavras, Caixa Postal 3037, 37200-000, Lavras, Minas Gerais, Brasil. maraisaht@yahoo.com.br; andrei_tiberti@hotmail.com ${ }^{2}$ Engenheiro-Agrônomo, Doutor. Departamento de Agricultura, Universidade Federal de Lavras, Caixa Postal 3037, 37200-000, Lavras, Minas Gerais, Brasil. rafaelpio@ dag.ufla.br (autor para correspondência).

${ }^{3}$ Engenheiro-Agrônomo. Mestrando do Programa de Pós-graduação em Fitotecnia, Departamento de Agricultura, Universidade Federal de Lavras, Caixa Postal 3037, 37200-000, Lavras, Minas Gerais, Brasil.madeleine_dede@yahoo.com.br; fbmsouza@yahoo.com.br
} 


\section{INTRODUÇÃO}

Os cultivos da amoreira preta (Rubus spp.) aumentaram, paulatinamente, nos últimos anos, principalmente no sul de Minas e na serra da Mantiqueira. O interesse dos produtores pelo cultivo dessa fruta deve-se ao recente aumento do seu consumo, como alternativa ao cultivo do morangueiro e, ainda, na possibilidade de agregação de valor na comercialização dos frutos produzidos via processamento na forma de doces (Pagot, 2006; Gonçalves et al., 2011).

Dentre as espécies do gênero Rubus ainda não exploradas no Brasil tem-se a Rubus fruticosus, de ocorrência na Europa e Austrália. Esta espécie possui potencial econômico pela qualidade de seus frutos, rusticidade e crescimento rápido; contudo, as pesquisas com ela realizadas são ainda escassas (Evans et al., 2004). Apesar de a literatura recomendar a utilização de estacas caulinares, provenientes de ramos retirados pela poda realizada no inverno (Antunes et al., 2000), as estacas radiculares são outra opção para produção de mudas de amoreira preta. A vantagem da utilização das estacas radiculares seria quanto ao seu manuseio, uma vez que a maioria dos cultivares comerciais apresenta ramos dotados de espinhos, em números variados, o que onera e dificulta a operação de preparo das estacas (Campagnolo \& Pio, 2012a).

No caso da amoreira preta, as estacas radiculares apresentaram maior percentagem de enraizamento e emissão de raízes, quando comparadas com as caulinares (Campagnolo \& Pio, 2012b). Por outro lado, estacas caulinares da framboeseira negra Rubus niveus demonstraram maior facilidade em brotar e emitir raízes, em comparação com as estacas radiculares (Silva et al., 2012). Com isso, verifica-se que a literatura apresenta divergência entre os resultados obtidos quanto ao uso de estacas caulinares e radiculares, dentro do gênero Rubus.

Uma técnica empregada na propagação por estacas em espécies frutíferas é a aplicação do ácido indolbutírico (AIB), auxina sintética que tem por finalidade acelerar o processo de emissão de raízes adventícias (Han et al., 2009). A aplicação de $2000 \mathrm{mg} \mathrm{L}^{-1}$ aumentou a emissão de raízes em estacas caulinares da amoreira preta 'Guarani' (Villa et al., 2003); porém, desfavoreceu a emissão de raízes em estacas caulinares e radiculares da amoreira preta 'Tupy' (Campagnolo \& Pio, 2012b). No caso do 'Boysenberry' (híbrido entre 'Marionberry' e framboesa), a aplicação de AIB em estacas caulinares diminuiu consideravelmente o enraizamento e a brotação das estacas (Tiberti et al., 2012).

O objetivo deste trabalho foi avaliar o enraizamento de estacas caulinares e radiculares de amoreira preta Rubus fruticosus, tratadas com AIB.

\section{MATERIAL E MÉTODOS}

Foram coletadas estacas radiculares e caulinares de plantas matrizes da espécie Rubus fruticosus, em plantas estabelecidas no pomar didático do Departamento de Agricultura da Universidade Federal de Lavras (UFLA), no mês de março de 2012. Posteriormente à coleta, as estacas radiculares foram padronizadas, em tamanhos de 10 $\mathrm{cm}$ de comprimento e diâmetro de $8 \mathrm{~mm}$ e, as caulinares, em $15 \mathrm{~cm}$ de comprimento e $10 \mathrm{~mm}$ de diâmetro, sem folhas, com corte horizontal no ápice e em bisel na base. Em seguida, as estacas foram imersas, por 10 segundos, em AIB, nas concentrações de 1000, 2000, 3000 e $4000 \mathrm{mg} \mathrm{L}^{-1}$, além do tratamento controle, que utilizou apenas água.

O delineamento utilizado foi o inteiramente casualizado, no esquema fatorial $2 \times 5$, sendo o primeiro fator composto pelo tipo de estaca (caulinar e radicular) e o segundo pelas concentrações de AIB, contendo quatro repetições e dez estacas por unidade experimental, totalizando-se assim 400 estacas.

As estacas caulinares foram enterradas a 2/3 de seu comprimento, em posição vertical, e, as radiculares, totalmente, na posição horizontal, na profundidade de $3 \mathrm{~cm}$. Foram utilizadas caixas plásticas com dimensões de $35 \times 20 \mathrm{~cm}$ e profundidade de $15 \mathrm{~cm}$, preenchidas com vermiculita de grânulos finos, que permaneceram dentro de telado com sombreamento de $50 \%$. As estacas foram diariamente umedecidas manualmente, com regador e, ao final de 60 dias após o estaqueamento, foram mensuradas as percentagens de enraizamento e brotação, o número médio de raízes e brotos e o comprimento médio das brotações.

Os dados foram submetidos a teste de normalidade, para verificar possíveis necessidades de transformação, que não foram detectadas. A seguir, foram submetidos à análise de variância e as médias comparadas pelo teste Tukey, a 5\% de probabilidade de erro para o fator qualitativo, e de regressão, para o fator quantitativo. Para a análise estatística, foi utilizado o programa Sistema para Análise de Variância - SISVAR.

\section{RESULTADOS E DISCUSSÃO}

Não houve interação entre os tipos de estacas e as concentrações de AIB, para todas as variáveis analisadas. No entanto, houve diferença entre os tipos de estacas e as concentrações de AIB, de forma isolada, para todas as variáveis, com exceção da percentagem de enraizamento, quanto ao tipo de estacas, e ao comprimento médio das brotações, quanto às concentrações de AIB.

Não houve diferença significativa quanto à percentagem de enraizamento, entre as estacas caulinares e radiculares de Rubus fruticosus (Tabela 1). Pelos resultados obtidos, verificou-se que a percentagem média de 
enraizamento entre os tipos de estacas foi de $34,2 \%$. Villa et al. (2003), trabalhando com estacas caulinares do cultivar Brazos (Rubus spp.), registraram 62,38\% de enraizamento, percentagem quase duas vezes superior à obtida neste trabalho. Ressalta-se que a potencialidade de uma estaca para formar raízes é variável com a espécie, ou mesmo, com o cultivar (Hartmann et al., 2002).

Para as demais variáveis analisadas (percentagens de brotação, número médio de raízes e brotos e comprimento médio das brotações), constatou-se que as estacas caulinares apresentaram resultados estatisticamente superiores, em comparação com as radiculares (Tabela 1). Houve incremento de $33,9 \%$ de estacas brotadas, quatro raízes emitidas e aproximadamente um broto a mais, além de 3,2 cm no comprimento médio das brotações, entre as estacas caulinares e radiculares.

É provável que a época de coleta das estacas tenha influenciado nos resultados obtidos. As estacas de Rubus fruticosus foram retiradas no outono, período em que ainda não haviam apresentado decréscimo no seu metabolismo e migração de substâncias para o sistema radicular. A influência da época de coleta na propagação de estacas caulinares de Rubus spp. também já foi constatada por outros autores. Campagnolo \& Pio (2012b) verificaram que estacas radiculares da amoreira preta 'Tupy' têm taxa de enraizamento e brotação favorecidas, quando coletadas no início do período hibernal. Os autores mencionam que neste período ocorre mobilização dos fotoassimilados para o sistema radicular, que auxiliam no enraizamento das estacas radiculares.

Silva et al. (2012) também constataram melhor desempenho de estacas caulinares em detrimento daqueles de estacas radiculares de framboeseira negra (Rubus niveus). Os autores constataram incremento na percentagem de estacas brotadas e no número de raízes de 45,7 e $11,7 \%$, em relação aos das estacas radiculares, respectivamente.

Quanto ao tratamento com AIB, observou-se decréscimo na percentagem de enraizamento e brotação com o aumento das concentrações desse regulador (Figura 1). As estacas tratadas com $4000 \mathrm{mg} \mathrm{L}^{-1}$ de AIB apresentaram percentagem média de enraizamento e brotação de 13,3 e $3,7 \%$, respectivamente, enquanto, sem a utilização do áci- do, os valores médios foram de 54,6 e 56,5\%, resultando na redução de 41,3 e 52,8\%. Os resultados indicaram que o tratamento com AIB torna-se dispensável no enraizamento de estacas caulinares e radiculares de Rubus fruticosus, quando coletadas no outono.

De acordo com Villa et al. (2003), estacas caulinares do cultivar de amoreira preta Brazos (Rubus spp.) apresentaram redução do enraizamento, quando tratadas com AIB, obtendo-se enraizamento médio de $62,38 \%$ sem o uso do estimulante. O mesmo foi constatado para estacas caulinares de 'Boysenberry' (híbrido obtido pelo cruzamento entre Rubus ursinus x Rubus idaeus), quando a aplicação de AIB nas estacas diminuiu consideravelmente seu enraizamento e brotação (Tiberti et al., 2012).

Os resultados sugerem que o uso do AIB provocou fitotoxidez às estacas e que o teor endógeno de substâncias promotoras do enraizamento é capaz de induzir este processo sem o uso de substâncias sintéticas, pois, além do decréscimo no enraizamento e brotação, houve decréscimo no número médio de raízes e brotos com o aumento das concentrações de AIB (Figura 2).

$\mathrm{O}$ efeito fitotóxico da suplementação exógena de auxina, desfavorecendo o número médio de raízes e brotos, também foi constatado por Silva et al. (2012) em Rubus niveus. Estes autores observaram que o tratamento com $1000 \mathrm{mg} \mathrm{L}^{-1}$ de AIB foi capaz de reduzir pela metade o

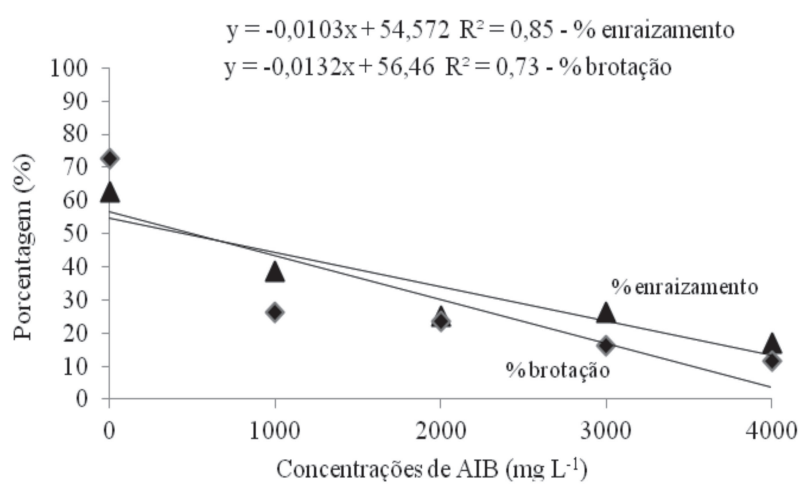

Figura 1. Percentagem de enraizamento e brotação de estacas caulinares e radiculares da amoreira preta Rubus fruticosus, submetidas ao tratamento com diferentes concentrações de AIB. Lavras, UFLA, 2012.

Tabela 1. Percentagem de enraizamento e de brotação, número médio de raízes e brotos e comprimento médio dos brotos de estacas caulinares e radiculares da amoreira preta Rubus fruticosus. Lavras, UFLA, 2012

\begin{tabular}{lccccc}
\hline \multirow{2}{*}{ Tipo de estaca } & \multicolumn{3}{c}{ Variável analisada } \\
\cline { 2 - 6 } & \% enraizamento & \% brotação & $\mathbf{N}^{\mathbf{0}}$ raízes & $\mathbf{N}^{\mathbf{0}}$ brotos & $\begin{array}{c}\text { Comprimento } \\
\text { brotos (cm) }\end{array}$ \\
\hline Caulinar & $38,0 \mathrm{a}$ & $47,0 \mathrm{a}$ & $7,4 \mathrm{a}$ & $1,3 \mathrm{a}$ & $3,7 \mathrm{a}$ \\
Radicular & $30,5 \mathrm{a}$ & $13,1 \mathrm{~b}$ & $3,4 \mathrm{~b}$ & $0,5 \mathrm{~b}$ & $0,5 \mathrm{~b}$ \\
\hline C.V. $(\%)$ & 26,8 & 37,8 & 26,8 & 30,4 & 30,4 \\
\hline
\end{tabular}

*Médias não seguidas pela mesma letra na coluna diferem entre si pelo teste Tukey, a $5 \%$ de probabilidade. 
número de brotos em relação à testemunha, além de causar decréscimo na ordem de 57,3\% para o número de raízes.

Similarmente ao que ocorreu para as demais variáveis analisadas, à medida que se aumentou a concentração de AIB, gradativamente houve redução no comprimento dos brotos (Figura 3).

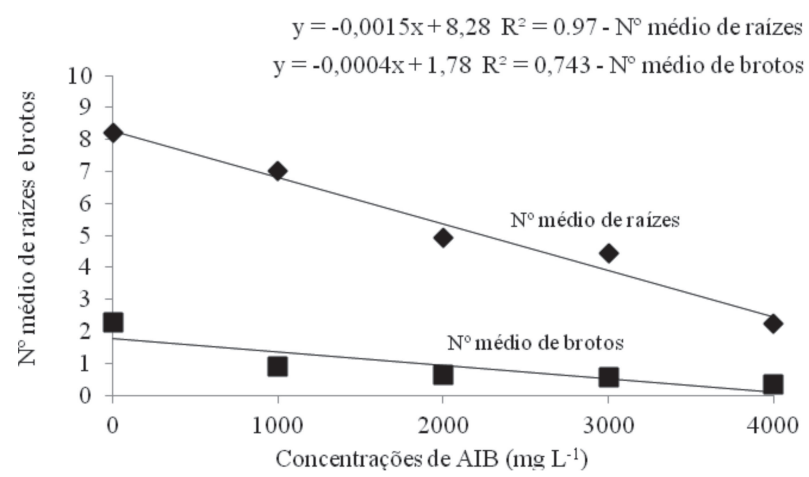

Figura 2. Número médio de raízes e brotações de estacas caulinares e radiculares da amoreira preta Rubus fruticosus, submetidas ao tratamento com diferentes concentrações de AIB. Lavras, UFLA, 2012.

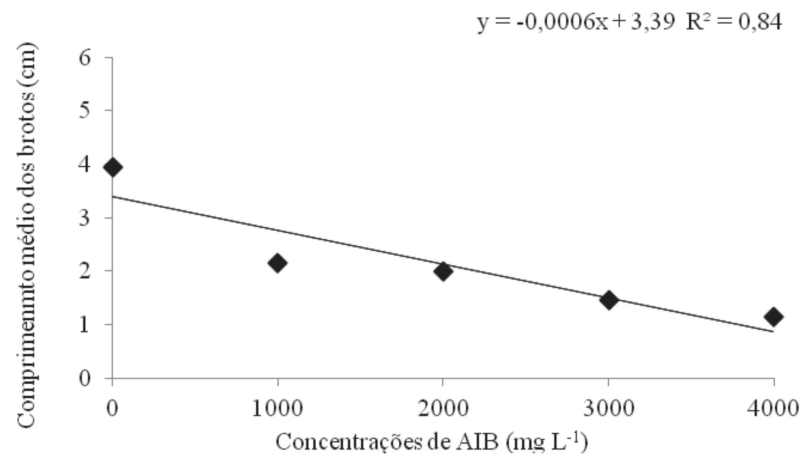

Figura 3. Comprimento médio das brotações de estacas caulinares e radiculares da amoreira preta Rubus fruticosus, submetidas ao tratamento com diferentes concentrações de AIB. Lavras, UFLA, 2012.

\section{CONCLUSÃO}

Pode-se concluir que as estacas caulinares apresentaram melhores resultados para formação das mudas, não se devendo tratá-las com AIB.

\section{REFERÊNCIAS}

Antunes LEC, Chalfun NNJ \& Regina MA (2000) Propagação de cultivares de amoreira-preta através de estacas lenhosas. Revista Brasileira de Fruticultura, 22:195-199.

Campagnolo MA \& Pio R (2012a) Phenological and yield performance of black and redberry cultivars in western Paraná State. Acta Scientiarum, 34:439-444.

Campagnolo MA \& Pio R (2012b) Enraizamento de estacas caulinares e radiculares de cultivares de amoreira-preta coletadas em diferentes épocas, armazenadas a frio e tratadas com AIB. Ciência Rural, 42:232-237.
Evans KJ, Symon DE, Whalen MA, Barker RM, Hosking JR \& Oliver JA (2004) Taxonomic update and Lucid key for introduced blackberry in Australia. In: $14^{\text {th }}$ Australian Weeds Conference, Wagga. Proceedings, Charles Sturt Univesity. p.509-512.

Gonçalves ED, Zambon CR, Silva LFO, Silva DF, Pio R \& Alvarenga AA (2011) Implantação, manejo e pós-colheita da amoreirapreta. Belo Horizonte, EPAMIG. 5p. (Circular Técnica, 144).

Han H, Zhang S \& Sun X (2009) A review on the molecular mechanism of plants rooting modulated by auxin. African Journal of Biotechnology, 8:348-353.

Hartmann HT, Kester DE, Davies Junior FT \& Geneve RL (2002) Plant propagation: principles and practices. $7^{\mathrm{a}}$ ed. New Jersey, Prentice Hall. 880p.

Pagot E (2006) Cultivo de pequenas frutas: amora-preta, framboesa e mirtilo. Porto Alegre, EMATER/RS-ASCAR. 41p.

Silva KN, Pio R, Tadeu MH, Assis CN, Curi PN, Moura PHA \& Patto L (2012) Produção de mudas de framboeseira negra por diferentes métodos de propagação vegetativa. Ciência Rural, 42:418-422.

Tiberti AS, Pio R, Assis CN, Silva KN \& Tadeu MH (2012) Propagação do 'Boysenberry' por estaquia e mergulhia. Ciência Rural, 42:423-428.

Villa F, Pio R, Chalfun NNJ, Gontijo TCA \& Dutra LF (2003) Propagação de amoreira-preta utilizando estacas lenhosas. Ciência e Agrotecnologia, 27:829-834. 